\title{
Family Unity Objectives of Parents Who Teach Their Children: Ideological and Pedagogical Orientations to Home Schooling
}

\author{
Maralee Mayberry and J. Gary Knowles
}

This article examines parents who teach their children at home. Using the results from two qualitative studies the article suggests, while families have complex motives for teaching their children at home, an important commonality underlies their decision. Regardless of their orientation to home schooling the parents in these two studies felt that establishing a home school would allow them to maintain or further develop unity within the family. The article suggests a family's decision to home school is often made in an attempt to resist the effects on the family unit of urbanization and modernization. The policy implications of this finding are discussed.

As we approach the end of the twentieth century, home schooling has become a popular educational alternative for an increasing number of families throughout the country. During the last decade the United States has seen a growing number of families reject institutionalized forms of schooling and opt for family-controlled learning. The actual number of children being educated at home is unknown, but conservative national estimates range from 120,000 to over one million (Feinstein, 1986; Holt, 1984; Lines, 1987, 1989; Moore, 1985).

The growing interest in home schooling reflects an assault on the revered position that compulsory formal education attained during the early part of the twentieth century. The presence and growth of home schools is also a reflection of economic, political, and cultural developments and conflicts that have occurred over the last two decades. Home school families are willing to take significant steps to protect their children from what they believe to be the

Maralee Mayberry, Department of Sociology, University of Nevada, 4505 Maryland Parkway, Las Vegas, NE 89154. J. Gary Knowles, School of Education, University of Michigan. 
erosive effects of modernization and secularization on the American family and public education. Families who educate their children at home are often dissatisfied with their diminished role in the decision-making process of public education and are increasingly concerned with what they perceive as the breakdown of the American family unit (Mayberry, 1988a).

Much of the available literature on home schools either advocates home schooling (e.g., Arons, 1983; Holt, 1981) or provides resource materials to those considering home schooling (e.g., Holt, 1981; Moore, 1985). Other treatments are found in the professional literature and are concerned primarily with providing judicial and legislative analysis (Harris and Fields, 1982; Lines, 1985) or information regarding home school learner outcomes (Perkel, 1979; Ray, 1988; Taylor, 1986; Tizard, Hughes, Pinkerton, and Carmichael, 1982). Although relatively few data-based studies on home school families have been conducted, a small number are now available. These sources provide information about the demographic characteristics of home school parents, case study reports of families who choose to home school, and discussions of the ideological and pedagogical issues surrounding home schooling.

Many of the existing empirical studies have focused on the demographics of home schools and the characteristics of parents who operate them (e.g., Gustavsen, 1981; Liden, 1983; Mayberry, 1988b; Taylor, 1986; Wartes, 1987). The quantitative studies are concerned primarily with identifying the geographical distribution of home school families, their educational, occupational, and income characteristics, and their religious, political, and educational attitudes. Moreover, several of these studies have also listed the reasons parents give for choosing to teach their children at home (e.g., Gustavsen, 1981; Linden, 1983; Wartes, 1987). Although most of the studies are limited by small sample sizes and sampling procedures (see Mayberry, 1988a; Wright, 1988), they have provided home school researchers with important descriptive information about the demographic and social characteristics of the growing number of families choosing to teach their children at home.

In addition to the quantitative research on home school families, a small number of qualitative studies have focused specifically on exploring the variety of motivations parents have for teaching their children at home. By conducting in-depth interviews with home school parents, researchers have been able to describe the experience of home schooling from the perspective of the parents and uncover various rationales parents have for starting home schools. These studies have provided rich anecdotal accounts of the parents' education-related experiences that influenced their decision to teach their children at home (Knowles, 1988; Knowles and Hoefler, 1988), and the ideological and pedagogical benefits parents hope to gain by home teaching (Mayberry, 1988a; Van Galen, 1986).

Researchers now have a general understanding of the demographic 
characteristics and religious, political, and educational attitudes of home school parents as well as the factors involved in their decision to teach their children at home. With this information in hand, it is time for researchers to move beyond descriptive and exploratory studies of home school parents and provide analytical discussions about why an increasing number of families are choosing to educate their children at home. This article takes up the challenge by examining the relationship between the underlying objectives parents have for choosing home-based education and wider social changes.

One goal of this article is to clearly elucidate the objectives many parents desire to achieve by teaching their children at home. By building upon previous works that have identified the primary rationales parents have for establishing home schools, we explore how these rationales not only pattern parents' beliefs about educational content and educational environments but also shape the objectives they hope to achieve by teaching their children at home. A second goal of the article is to locate our findings within a wider social context. That is, we examine how the complex motives and goals of home school parents are related to modernization trends in American society. Finally, we suggest that our findings hold particular importance for policymakers. Policymakers need to take seriously the desire of home school parents to strengthen the family unit as they engage in formulating policies that determine the degree to which parents will be allowed to make decisions about their children's educational experience.

\section{THE OREGON AND UTAH STUDIES}

The findings in this article are based on the results of two independently conducted studies. One investigation, a statewide study of home school families in Oregon, was conducted during 1987 and 1988 (Mayberry, 1988a). The other, conducted in Utah's most heavily populated region, the Wasatch Front, began in 1985 and continued as part of a larger study (e.g., Knowles and Hoefler, 1988). When combining the results of the two studies we were intrigued to discover an important commonality among a diverse group of parents who home school. Before discussing these findings, however, we would like to provide a more specific description of each study.

\section{The Oregon Study}

In order to learn about the Oregon home school population, a two-stage research design was developed that generated detailed information about home school parents. First, a questionnaire with 154 variables was mailed to 1,600 home school families throughout the state of Oregon. Approximately half of the questions were open-ended and yielded an abundance of data. Respondents were 
asked to describe the various factors that contributed to their decision to home school and to discuss why home school was their favored choice, rather than enrolling their children in private or church-related schools. Moreover, parents were asked to describe the benefits they believed children and families gained from the home school experience.

Home school families who received the survey were identified from the registration lists of Oregon's Educational Service Districts, the membership lists of various Oregon home school support groups, and the subscription list of Teaching Home magazine, a publication that provides curriculum and legal information to mainly religiously oriented home school families. In addition, the directors of several alternative private schools provided the names of families who they knew taught their children at home. Given that many home school parents are suspicious of social research, which in their perception could be used to curb their fundamental right to control the education of their children (Harris and Fields, 1982; Lines, 1985), we were satisfied with obtaining a 35\% response rate. The variety of distribution techniques used resulted in participation by families whose orientations to home schooling were similar to those identified by other home school researchers (e.g., Wartes, 1987; Van Galen, 1986; Pitman, 1987). From this data four categories of home school parents were identified; religious, sociorelational, academic, and New Age. ${ }^{1}$

Second, in-depth interviews were employed to further explore the rationales parents had for choosing to teach their children at home and to better understand the objectives they hoped to achieve. The categories that resulted from the analysis of the qualitative portions of the survey aided in the construction of the interview schedule and guided the choice of families for face-to-face interviews (see Mayberry, 1988a). Dimensional sampling (Arnold, 1970) was used to select 15 home school families that represented the significant dimensions along which the surveyed families varied. The parent participants were asked to explore the relationship between their biographical sketches, the social context of their lives, and their decision to home school. Following the "constant comparative" procedure described by Glaser and Strauss (1967), similarities and differences in parents' orientations to home school and objectives for home schools emerged.

The results of the Oregon study fulfilled two objectives. First, qualitative portions of the survey and follow-up interviews identified the primary orientations parent had to home schooling. Second, examination of the data revealed several common objectives that families from each orientation hoped to achieve by teaching their children at home.

\section{The Utah Study}

The purpose of the Utah study was to understand more clearly what parents hoped to achieve by teaching their children at home and to examine the ways 
parents think about their objectives for home schooling. The study, part of an ongoing ethnographic investigation (see Knowles, 1987, 1988), sought to sift out the human elements of home schools and to provide insiders' views concerning the importance of establishing a home school. Data were collected using a variety of approaches including written life history accounts, structured interviews, observations, and personal journals. The data were analyzed according to the principles of the "constant comparative" method (Glaser and Strauss, 1967).

Gustavsen's (1981) demographic profile of home school parents guided the selection of divergent families so as to maximize the scope of viewpoints (Goetz and LeCompte, 1984; Yin, 1984). The sample was drawn from the home school population of the Wasatch Front region of Utah-from Provo in the south, to Ogden in the north, including Salt Lake City-based on diversity of their characteristics including socioeconomic and occupational status, religious and political orientation, residential location, lifestyle, length of time involved in home schooling, parental education, and commitment to the long-term study. Home school families were initially contacted at the annual convention of the Utah Home Education Association and through other association events. Eight of these families were eventually selected for participation.

The life history accounts were obtained by using structured discussion topics designed to initiate extensive open-ended written responses. The discussion topics motivated parents to report past, present, and future home school concerns and activities. The data obtained related to rationales and teaching methods and included biographical information about childhood education and family experiences; historical events important in the establishment of the home school; relations with, and reactions of, family, neighbors, and community; interaction with school principals; preparation for home schooling; childhood learning experiences; positive and negative teacher role models; school memories; teaching experiences; beliefs about education; and current relations between parents and their children. Interviews defined issues arising from the life histories and clarified hypotheses and questions generated from previous ongoing analyses (see Knowles, 1987, 1988). Five of the families agreed to write structured journal entries, reflecting on the activities and feelings of a selected week of home schooling as related to family interactions and relationships.

From these data the objectives many families had for home schooling as they related to family interactions emerged. For instance, the study identified four issues of central importance for home school families: control, protection, self-actualization, and closeness. ${ }^{2}$ The results of the study were organized around these issues and gave evidence of the complex objectives for home schooling that many parents strive to achieve. 


\section{Comparison of the Oregon and Utah Studies}

We feel that the similarities and differences between the two studies strengthen our discussion of the underlying rationales parents have for starting home schools. For instance, the Utah study extended the Oregon study by using a variety of additional data collection approaches including written life history accounts, structured interviews, observations, and personal journals. The data, however, were analyzed in a similar fashion in both studies, providing complementary findings. Furthermore, the criteria used in the Utah study to select interview subjects expanded the range of parental characteristics included in the Oregon study, thus providing a wider diversity of parents to be included in this report. Finally, although the analytical categories used in each study to describe parents' objectives for home schooling differed (in Oregon, parents were oriented to home schooling for religious, sociorelational, academic, or New Age reasons; in Utah, orienting characteristics included protection, control, self-actualization, and closeness), when comparing the results of each study we found the central issues discussed by parents in each category to be similar and to crosscut our analytical categories.

What emerged from both studies were most useful insights into the family unity objectives of parents who teach their children at home. Specifically, by combining the results of both studies we discovered an important commonality among families who home school. Although home school families in both studies, to varying degrees, express their discontent with public school curricula, standards, and with the social and educational environment of public schools, most express the importance of family relationships and family unity in their decision to teach their children at home. These parents see teaching at home as an essential element in developing close family relationships. Although we have condensed the perspectives of home school families, more extensive descriptions of their orientations and their objectives for home school are given in separate reports of each study (see Knowles, 1988; Mayberry, 1988a).

\section{ORIENTATIONS AND OBJECTIVES OF HOME SCHOOL FAMILIES}

In a brief historical sketch, Berger and Berger (1983) trace the effects of modernization and industrialization on the American family, making the case that with the proliferation of new social institutions the traditional functions performed by the family have been greatly attenuated. Historically "new" institutions, such as public education, compete with the family in providing educational, moral, and social guidance.

Berger and Berger claim that the history of the family cannot be conceptualized properly without understanding that social change is the result interaction between institutions and consciousness. The implications of this 
active view of the family, they point out, is that the family can be seen as the "locale of demodernizing forces" (p. 106); no topic emphasizes this point more clearly than that of education. The contemporary American family has not simply accepted the expropriation of its educational functions by modern institutions of education but has continually sought a participatory voice in educational decisions. Home schooling is only one dimension in which this participatory voice has been obtained.

Our studies of home school families underscore this point. The orientations and objectives of families who teach their children at home reflect their resistance to child-socialization functions becoming increasingly a professional task outside the realms of family influence. We now provide a closer examination of those objectives and orientations. ${ }^{3}$ The analytical distinction between ideological and pedagogical home school families that we will use in the following sections was originally developed by Van Galen (1986).

\section{Ideological Orientations and Family Relationships}

One broad category of home school families is orientation to home schooling for ideological reasons. These parents advocated an education for their children that was organized and controlled by parents rather than the state. Critically important to most of the parents was control over the content of material and lessons their children learned. Ideologically oriented home school parents implemented their own philosophy within the home school by devoting time and energy planning and carrying out lessons that reflected the type of knowledge and experiences they wished to transmit to their children. Having control over the curriculum ensured that children were exposed to what the parents believed was good for them.

Many ideologically oriented families are motivated by their religious beliefs to begin home schooling. Their home school activity can only be understood within the context of their religious philosophy, the secular orientation of pubic schools, and their concern about family issues. The major themes that oriented the home school decision of religious families were gleaned from the interviews conducted in both Utah and Oregon and included their "God-given right to be responsible for their children's education"; their desire "to save society and their children from secular influences and the evils embodied in the humanistic ideology of public schools"; and their desire to restore the primacy of the family in educational affairs. One home school father in Oregon, writing for a religious home school newsletter, summed up the feelings of many religious home school parents with the following comment:

We are a very typical home school family in this one regard: We believe that we are commanded by God, and responsible to God, to bring up our children according to His 
Word. . . . The responsibility of a father to train and direct his family cannot be delegated to the school.

It is funny; if we were to ask someone, "Whose responsibility is it to feed your children?" the response would certainly be, "Why, my responsibility, of course." If we were to ask, "Whose responsibility is it to clothe your children?, Who is responsible to love them, to make sure that they have all of their physical needs met?," there would be no hesitation in replying, "These are my children. I am responsible for their needs." And yet, so many people, when asked, "Whose responsibility is it to educate your children?," reply, "The State's" or "The school's" without a second thought.

We see the responsibility to educate our children as being as essential as feeding, clothing, and providing for them. . . . Because we love our children, and because we feel that it is the command of God, we home school them.

While religious ideologies oriented many families to home schooling, a smaller group of parents subscribed to the ideology associated with New Age philosophy. These parents came to home education with a world view that profoundly shaped their perception about the function of education, the role of the family in education, and the ideologies that education should embody. The social crisis of our times, they believed, stems from an inability to see reality as an interrelated whole. The solution, they argued, is the development of a new culture based on a consciousness that is able to perceive all facets of the human experience-rational, emotional, and spiritual-as wholly and intrinsically connected to the development of the universe. Establishing home schools allowed New Age parents to foster this consciousness in their children. Two Oregon mothers made the following comments during in-depth interviews about why they had chosen to teach their children at home and typify the New Age position:

We attempt to live a spiritually integrated life, with love, reverence, and respect for all life. . . . Home schooling allows us to teach this.

I doubt if there's a school espousing the belief systems of oneness with nature, Native American traditional beliefs, Sufism, Buddhism, etc. I wish for acceptance of intuitive thought and less rational learning.

Although different ideologies orient religious and New Age parents to home schooling, they shared the objective of developing or maintaining close relationships within the family. For these parents, home schooling was intricately connected with the development of family unity. It was important for the parents to have their children's active participation in family activities, of which schooling at home was only one of many unifying activities.

These parents stressed the importance of parent-child bonding for understanding the educational needs of children. Their home school activities represented their conviction that a child's education should be the responsibility 
of the parents, not the school, and the vehicle by which parental bonding and family unity could be obtained. One father summarized his feelings about family unity in a home school newsletter by paraphrasing a passage from the Bible:

Whatever else may be said about the family, it is the bedrock of life. . . It is the single most influential force in our early existence. Through quality programs and family-centered activities, lives are being built and re-built according to the divine blueprint. (Psalm 127:1)

This group shared the sense that control of a child's education guaranteed not only their ability to monitor the content of the curriculum but to ensure strong family ties. One mother explained that home schooling allows her child to be imbued with her family's values and experiences:

Our child wanted to share our home values; vegetarianism, living lightly on the earth, farming, labor intensive verses, [an] energy consumptive lifestyle, [and] non-materialism.

The desire to control the ideological content of their children's education oriented these families to home schooling, while enhancing family relationships, maintaining family bonds, and strengthening family ties were their desired objectives. By transmitting to their children their own ideological views they hoped to protect their children from "undesired" ideologies or social influences that could potentially fragment the family's values and system of beliefs. For these families, then, family unity is strengthened by the home school experience where control of the content of a child's education is not relinquished to the institution of public schooling.

\section{Pedagogical Orientations and Family Relationships}

Another category of parents who home school questioned the ability of public schools to provide educational programs and learning environments conducive to the academic and social development of their children. These parents were less concerned about the ideologies of public schools; rather, they were more concerned with the social and educational climate of public schools. They were not united by any particular world view, but believed that they, as parents, were better able than schools to provide their children with positive and nurturing learning experiences. For them, the pedagogical orientation of education rather than the ideological content was at stake.

These parents viewed their children as unique individuals. They had experienced classrooms where individuality was often not recognized or they perceived that their children's schooling experience was not individualized. They were concerned about the "proper development" of their children's 
abilities. Families strongly expressed high ideals and expectations that they wanted to implement in their children's education. Home school was their choice of educational approaches best suited to nurture their children.

For some pedagogically oriented parents, educating at home was seen as the "best way" to promote the intellectual development of their children. One mother interviewed in Oregon explained:

We truly believe we do better with one-on-one than the schools can [do] at the present time. The nurturing that takes place within the home in academic areas could never be provided by an institution.

Many parents were concerned with educational standards. They argued that public school standards were too lenient and mediocre, and that a home-based education could insist on more rigorous standards. Some parents interviewed felt that children need to be "pushed to their personal achievement," which can only occur when children are given extensive individual attention. These parents contended that home schooling provided the individual instruction and motivation necessary for children to realize their academic potential. Some of these parents had children who were either academically advanced or behind grade level and, for them, home school provided the solution to their dilemmas. During in-depth interviews, two Oregon mothers explained:

Josh was able to move faster than the school was set up to more. He was bored and becoming decreasingly motivated. . . . We [the parents] are better able to supply the personal, individual input he needs.

Monica did fine the first year in public school but something went wrong the second year. . . Monica started saying how stupid she was. . . Finally things got so bad I had to drag her kicking and screaming to the school bus. I'd go up and visit at the school unannounced; Monica would be just sitting there staring into space. . . . I managed to get her out of school and we did everything at home from then on.

Other parents were concerned with the pedagogical environment, more specifically the social climate, of public schools and the effect of that environment on their children's social development. Many wished to protect their children's moral development from perceived divergent societal values and a "degenerate morality." They also wanted to protect what they felt was their children's unique sensitivities and feelings from real or perceived unpleasant, stressful, or competitive situations in schools. One mother interviewed in Utah, for example, felt that thought home schooling her children became "more confident and happy about themselves" because they did not confront daily peer pressures. Another parent in Utah was dismayed at the "obnoxious behaviors" the children learned at school-behaviors "that they would not learn at home."

Some pedagogically oriented parents saw home school as a natural continuation of the learning process between parent and child that was initiated 
in infancy. These parents desired to create a warn and safe learning environment for their children and to protect their children from a "certain harshness" found in schools. One Utah mother felt that learning in the home "triggers aspect of though and personality not usually learned [in school] . . ; it instigates growth and thinking." Another mother in Oregon simply believed that the safe environment of the home allowed her children to "do better in many areas; intellectually, creatively, and socially."

Like parents who home school for ideological reasons, the desire to maintain or restore family unity was a common thread uniting the home education decision of pedagogically oriented parents. Mothers of children who had never been enrolled in public school frequently wrote comments on the Oregon survey such as, "Keeping them at home just felt natural, right, and comfortable." Others who removed their children from public schools in order to teach them at home discussed the changes within the family unit that had occurred. For instance, one Oregon mother commented during an interview that she did not realize what an impact home schooling would have on family bonding: "Our children are [now] closer and they respect us more." Close parent-child bonding was a primary objective for teaching children at home. Several other parents in Oregon explained:

We were a very close family and we heard of the home schooling option at the time [when our son was of school age]. "Why not continue building the close relationships that we had been working on for the past five years?," we reasoned. Our son's best friend is his teacher, his mother. We like it that way.

We feel our family unit is strengthened by the time spent in learning and playing together. The more time [together], the stronger the family!

The bottom line is that I was not ready to let them go off [to school]. I didn't want to get rid of them and can't understand mothers that look forward to school starting to get rid of their kinds.

Pedagogically oriented parents, especially mothers, felt the need to be with their children during their early years so that the foundations of family unity could be laid. Others merely expressed their desire to share in the development of their children. For whatever reason, these parents shared the feeling that the time demanded attending public schools was time better spent by children at home. One mother interviewed in Utah explained the importance of "home time" by commenting: "I would like to do all I can to be with my child and [to] help [her] as much as I can." Another Oregon parent expressed clearly the relationship between home schooling and family unity by answering a survey question about why she has chosen home school with the following comment:

Some of us [home school parents] love our children and enjoy being close to them; teaching them and watching them grow up under our own eyes. . . . I enjoy being with this child, I love her company, and I like watching her grow [more] smart. 
The themes running throughout the stories told by pedagogically oriented home school parents did not focus on the ideological messages of public schools or on their opposition to schools, but on the desire to provide their children with a learning climate that emphasized such pedagogical conditions as one-on-one learning, high academic standards, and what they considered healthy social growth. Like ideologically oriented parents, however, strengthening family relationships was a major objective of pedagogically oriented parents in their decision to teach their children at home. Sharing the experience of teaching and learning, spending time together, talking with each other, and sharing ideas were all things that both ideologically and pedagogically oriented parents felt had strengthened family bonds.

\section{CONCLUSIONS AND POLICY IMPLICATIONS}

At the beginning of this article we discussed several previous studies that identified the varieties of reasons parents have for starting home schools. This article expands on these existing conceptualizations by revealing a common concern of home school parents regardless of their ideological or pedagogical orientations to home schooling. By identifying common themes and concerns of parents who home school, this study moves the research in the direction of understanding the social context surrounding the emergence of the home school educational alternative.

The body of this article focused on how parents think about their relations with their children in the home school setting. In particular, we uncovered some patterns of how parents' beliefs and values about educational content and educational environments orient them toward home schooling, and ways in which parents see home schooling as working toward strengthening the family unit.

The results suggest complex motives for operating home schools: motives that are often intertwined with goals of family relationships. Generally parents chose to home school either because they wanted to control the ideological content of the curriculum or because they wanted to provide their children with what they perceived to be a superior educational and social environment. Although different orientations to home schooling appeared, all parents, regardless of their orientation, expressed a desire for maintaining or further developing the family unit. The chief mechanism to achieve or maintain family unity was seen to be the operation of a home school where the control of a child's education and time with a child is not relinquished to the institution of public schooling.

In this sense, Berger and Berger's (1983) activist view of the family becomes relevant. They argue that as social institutions become increasingly differentiated, rationalized, and secularized, people take an active role in sustaining a stable world view and maintaining the symbolic universes that convey meaning 
and give order to reality. The findings of this study suggest that the activity of home schooling may be a symbolic response to an increasingly differentiated, rationalized, and secularized school system.

We have seen that although families begin home school for different reasons, several common themes unify their action: their desire for family unity, their desire to protect or isolate their children from unwanted ideologies or influences, and their desire to either reclaim or not relinquish control of their children's education to public institutions. Home schooling, in this sense, provides families with the means not only to protect their children from the ideologies, values, and practices of public schools but to actively preserve world views and meanings that offer stable guidelines by which to live. In other words, it allows them to actively construct and maintain the meaning systems through which they make sense of the world during a period of increased sociocultural pluralism, intense bureaucratization of social institutions, rapid cultural change, and increasing differentiation between private and public spheres of human activity.

If one views the contemporary family as children's major source of meaning, values, and identity, and takes seriously the family's capacity to initiate new social processes (in this case, home schooling), then policy decisions about the degree to which parents are allowed to make decisions for their children must be undertaken with utmost seriousness. As Van Galen points out, "Becoming a home schooler is not only a pedagogical decision. It is also a public declaration of the parents' beliefs in the institution of the family" (1988, p. 104). While other researchers (Knowles, 1989; Mayberry, 1988a; Van Galen, 1986, 1988) have suggested what policymakers can learn from their studies, none have explicitly linked their policy recommendations to the underlying concern of home school parents to preserve family unity by playing a significant role in the education of their children.

It is our hope that articles such as ours will help professional educators and policymakers gain a clearer understanding of home schools and the parents who operate them and intelligently develop home school policies. By illuminating the importance of family relationships and family unity in the decision of parents to teach at home, educators may begin to feel less threatened by the increase in home school activity and more apt to engage in constructive efforts to explore enacting policies of cooperation between public and home schools (see Knowles, 1989). Policies directed toward increasing the involvement of parents in public education, as witnessed by the recent changes in Chicago schools and increasing the involvement of public schools in the lives of home-educated children could positively build upon not only the fundamental desire of home school parents to enhance family relationships but also the mission of public schools to best serve their communities.

We suggest that the polarization of home school families and public school 
policies often obscures major interests shared by both camps, as the recent events prior to the compromise between home school parents and public school officials in New York illustrate (see Layton and Purrington, 1989). As a further example of the obscured common interests, the president of the National Education Association appeared oblivious to the public school-home school commonalities in her comments about a recent Carnegie Foundation report stating that $90 \%$ of the teachers surveyed identified lack of parental support as a problem at their school:

I wish I could sit down with every parent in America and emphasize how important they are to their children's education. Parents are a child's first-and potentially the most influential teachers. (Associated Press, 1988)

There has been considerable research on the benefits of parental participation in the education process (see Berger, 1983). It is clear that parental involvement raises student achievement. The benefits of parental participation, however, accrue not only to students but to the parents themselves and schools as well. Herman and Yeh (1980) suggest that involved parents develop more positive attitudes toward schools as they become actively engaged in school programs; school program benefit as parents become increasingly able to articulate their children's educational needs. Moreover, research conducted by Armor, Bowles, and Filipczak (1976) suggests that parental involvement programs encourage parents to support not only public school programs but also to enlist support from the wider community, thus involving more parents in their children's educational experiences.

Home school policies aimed at developing home/public school partnerships could be a potentially important link in helping secure the positive effects of parental involvement. Knowles (1989) has suggested several policy recommendations that deserve further attention.First, federal and state agencies could adopt a proportional funding scheme where districts receive tax monies for home school children in proportion to the involvement of those children in district programs. Second, advisory and facilitatory services could be offered by public schools to home school parents. Such services would serve not only a regulatory function but would allow an exchange of information and ideas between education professionals and home school parents. Third, home school parents could become involved in the affairs of the school by belonging to school committees, the PTA, and other community-school affair groups. Finally, home school children could be encouraged to participate in public school functions and activities (e.g., band, choir, art, vocational classes, or sport activities).

Partnerships between communities and school districts, homes and schools, and teachers, parents, and learners could potentially be the most beneficial arrangement for constructing cooperative relationships between pubic institu- 
tions and private interests. It makes no sense to continue to alienate concerned parents from the public school arena, particularly those concerned about the preservation of the family unit. This fact is especially so in the present climate where the media continually bring to the viewer's and reader's attention the fragmentation of, and forces working against, the family.Home school families may indeed provide good examples of one way to preserve the family. Since both parents and schools have a role in education, such partnerships could represent a common effort toward common goals and best serve the interests of society, parents, and children.

\section{NOTES}

1. Oregon home school parents were categorized along the following dimensions: Religiousparents primarily concerned with what they perceive as a family right, rather than a state right, to take charge of the education of their children; parents who believe it is their duty to instill particular religious beliefs and values in their children. Academic-parents who feel public school do a poor job of addressing the special academic needs of their children; parents who believe home school motivates children to learn more because it allows one-on-one teaching. Sociorelational-parents who question the ability of public schools to provide learning environments conducive to the social development of children; parents who feel home-based instruction provides a superior social and educational environment; parents with an explicit desire to restore family unity and increase their personal involvement in educational matters. New Age - parents who desire to provide children with cultural beliefs and values that are consistent with the New Age philosophy; parents who desire to instruct their children in the interrelatedness of all life and nurture in their children a spirituality that emphasizes peaceful coexistence with others.

2. Utah home school parents were categorized along the following dimensions: Control-parents concerned about maintaining control over their children's learning activities, growth, development, and loyalty; parents who perceive outside influences, such as the state, as a challenge to their control. Protection-parents concerned about protecting their children's moral development and family values from perceived divergent societal values and morality; parents who seek to protect what they feel is their children's unique sensitivities and to protect their children from situations that are potentially incongruous with family values and the best way to promote the intellectual development of their children; parents who feel individual attention is needed for the development of their children's unique creativity and potential. Closeness parents concerned about the close nature of relationships within the family itself; parents who see home school as greatly increasing the interdependence of family members.

3. Greater detail regarding the data sources and settings can be obtained from the authors.

\section{REFERENCES}

Armor, D., Bowles, W. and Filipczak, S. (1976). Analysis of School Preferred Reading Program in Selected Los Angeles Minority Schools. Santa Monica: California Rand Corporation.

Arnold, D. O. (1970). Dimensional sampling: An approach for studying a small number of cases. The American Sociologist 5(2): 147-150. 
Arons, S. (1983). Compelling Belief: The Culture of American Schooling. Amherst: MA: University of Massachusetts Press.

Associated Press (1988). Teachers express frustration over lack of parental support. Las Vegas Register Journal, December 10, p. 8.

Berger, E. H. (1983), Beyond the Classroom: Parents as Partners in Education. St. Louis: C. V. Mosby Co.

Berger, B., and Berger, P. (1983). The War Over the Family. New York: Doubleday Press.

Feinstein, S. (1986, October). Domestic lessons: Shunning the schools, more parents teach their kinds at home. Wall Street Joumal, pp. 1, 24.

Glaser, B., and Strauss, A. (1967). The Discovery of Grounded Theory. Chicago: Aldine Press.

Goetz, J., and LeCompte, M. (1984). Ethnography and Qualitative Design in Educational Research. Orlando, FL: Academic Press.

Gustavsen, G. A. (1981). Selected characteristics of home schools and parents who operate them. (doctoral dissertation, Andrews University) Dissertation Abstracts International 42(10): 4381-4382A.

Harris, J., and Fields, R. (1982). Outlaw generation: A legal analysis of the home-instruction movement. Educational Horizons 61(1): 26-52.

Herman, J., and Yeh, J. (1980). Some effects of parent involvement in schools. Center for the Study of Evaluation. Los Angeles: University of California.

Holt, J. C. (1981). Teach Your Own. New York: Delacorte Press.

Holt, J. C. (1984, October). How schools can cooperate with home schoolers. Education Digest 49: $2-5$.

Knowles, J. G. (1987). Instructional patterns and practices in the home school: An exploratory case study of three Utah families. Paper presented at the annual meeting of the Northern Rocky Mountain Educational Research Association, Park City, UT.

Knowles, J. G. (1988). Parents' rationales and teaching methods for home schooling: The role of biography. Education and Urban Society 21(1): 1-11.

Knowles, J. G. (1989). Cooperating with home school parents: A new agenda for public schools? Urban Education 23(4): 392 -410.

Knowles, J. G., and Hoefler, V. (1988). Enhanced family relationships in the home school: Bonding or typing the apron strings? Paper presented at the annual meting of the American Educational Research Association, San Franeisco, CA.

Layton, D., and Purrington, G. (1989). The home school movement in New York State: The making of a historic compromise. Paper presented at the annual meeting of the American Educational Research Association, San Francisco, CA.

Linden, N. J. (1983). An investigation of alternative education: Home schooling (doctoral dissertation, East Texas State University). Dissertation Abstracts International 44(12): 3457 A.

Lines, P. M. (1985). Compulsory Education Laws and Their Impact on Public and Private Education (Report No. LEC-84-11). Denver: Education Commission of the States.

Lines, P. M. (1987). An overview of home instruction, Phi Delta Kappan 68(7): 510-517.

Lines, P. M. (1989). Home instruction. Paper presented at the annual meeting of the American Educational Research Association, San Francisco, CA.

Mayberry, M. (1988a). Doing it their way: A study of Oregon's home schoolers. (doctoral dissertation, University of Oregon). Dissertation Abstracts International 49(12): 3875A.

Mayberry, M. (1988b). Characteristics and attitudes of families who home school. Education and Urban Society 21(1): 32-41.

Moore, R. S. (1985). It depends on your aim. Phi Delta Kappan September: 62-64.

Perkel, F. E. (1979). The effects of a home instruction program on the cognitive growth af a selected group of 4-year-olds (doctoral dissertation, University of Southern California). Dissertation Abstracts International 40(4): 1859 A. 
Pitman, M. A. (1987). Compulsory education and home schooling: Truancy or prophecy. Education and Urban Society 19(3), 280-289.

Ray, B. (1988). Home schools: A synthesis of research on characteristics and learner outcomes. Education and Urban Sociery 21(1): 16-31.

Taylor, J. W. (1986). Self-concept of home-schooling children (doctoral dissertation, Andrews University), Dissertation Abstracts International 47(8): 2809A.

Tizard, B., Hughes, M., Pinkerton, G., and Carmichael, H. (1982). Adults' cognitive demands at home and at nursery school. Journal of Child Psychology and Psychiatry 23(2): 105-116.

Van Galen, J. (1986). Schooling in private: A study of home education (doctoral dissertation, University of North Carolina). Dissertation Abstracts International 40(5): 1683A.

Van Galen, J. (1988). Becoming home schoolers. Urban Education 23(1): 89-106.

Wartes, J. (1987). Report from the 1986 Homeschool Testing and Other Descriptive Information About Washington's Homeschoolers. Woodinville, WA: Washington Homeschool Research Project.

Wright, Cheryl (1988). Home school research: Critique and suggestions for the future. Education and Urban Society 21 (1): 96-113.

Yin, R. K. (1984). Case Study Research. Beverly Hills: Sage. 